Running Head: LOW-INTENSITY CBT FOR DEMENTIA CAREGIVERS

A meta-analysis of low-intensity cognitive behavioural therapy-based interventions for dementia caregivers

\title{
Laura Kaddour
}

Department of Clinical Psychology, Norwich Medical School, University of East Anglia, Norwich, UK

Dr Naoko Kishita

School of Health Sciences, University of East Anglia, Norwich, UK

Anthony Schaller

UK

Correspondence concerning this article should be addressed to Laura Kaddour, Department of Clinical Psychology, Norwich Medical School, University of East Anglia, Norwich, NR4 7TJ, UK. Email: L.Kaddour@uea.ac.uk. 


\begin{abstract}
Objectives: This study aimed to review the effectiveness of low-intensity cognitive behavioural therapy (CBT)-based interventions for informal dementia caregivers, when compared to non-active control conditions.

Design: Literature searches were conducted in databases of published (PsycINFO; MEDLINE; CINAHL; Scopus) and unpublished (Open Grey; ISRCTN registry;

ClinicalTrials.gov; ProQuest) literature. Individual meta-analyses were conducted for each outcome variable. Pooled intervention effect estimates were calculated as Hedge's $g$ using a random-effects model.
\end{abstract}

Included studies: Studies examining the effect of low-intensity CBT-based interventions for informal caregivers for people with any progressive dementia were included. Randomisedcontrolled trials and controlled clinical trials were included.

Measurements: Outcomes included the psychological variables of anxiety, depression, burden and distress (defined as stress or strain).

Results: A total of five studies reported anxiety outcomes, twelve reported on depression, three reported on burden and six reported distress outcomes. Results demonstrated a significant effect of low-intensity CBT-based interventions in reducing all examined psychological difficulties. Small effects sizes were found for anxiety $(g=0.35)$, depression ( $g$ $=0.27)$ and distress $(g=0.33)$. A medium effect was found for burden $(g=0.53)$.

Conclusions: The results provide initial support for low-intensity CBT-based interventions for dementia caregivers. Clinical implications and research recommendations are explored. Strengths and limitations of the study are discussed.

\title{
Keywords
}

Dementia caregivers; cognitive behavioural therapy; CBT; low-intensity; anxiety; depression; burden; distress 


\section{Introduction}

Dementia illnesses have a degenerative impact on the neurocognitive abilities of those affected (Knapp et al., 2007). Dementia is associated with significant behavioural changes and is both progressive and incurable (McKeith and Cummings, 2005). As such, the care needs for people with dementia generally increase as the disease progresses (Knapp et al., 2007).

Many people with dementia are cared for by informal caregivers who are often family members (Friedman et al., 2015). Caring for a person with dementia can have a negative impact on the carer's physical, financial, social and psychological wellbeing (Brodaty and Donkin, 2009; Bennett et al., 2013). Dementia caregivers (DC) are more likely to experience burden, depression, anxiety and stress compared to both the general population and caregivers for people with other illnesses (Schulz et al., 1995; Bertrand et al., 2006). Furthermore, psychosocial difficulties in DCs have been associated with an increase in care recipients being placed in formal residential care (Brodaty and Donkin, 2009).

This is important given that the global prevalence of dementia was estimated at 35.6 million people in 2010 , with a prediction that this number will double every 20 years (Prince et al., 2013). As such it is expected that there will be an increase in the need for informal care. The need for informal care may be greater in less developed countries, where access to formal care is more limited, and in countries with chronically underfunded health and social care systems (Prince et al., 2013; Franca, 2017).

Concordantly, the need to develop effective, low-cost, and accessible interventions for DCs has been recognised by the World Health Organisation (World Health Organisation, 2012). Currently, a variety of DC interventions exist, addressing the wide range of difficulties associated with caregiving. Such interventions include providing education about dementia and caregiving, respite care, general support, psychological 
interventions and multi-component interventions which may combine aspects of several types of intervention (Pinquart and Sörensen, 2006).

Previous comprehensive reviews of DC interventions suggested that psychoeducational programmes and Cognitive-Behavioural Therapy (CBT) can impact on the wellbeing of DCs, with the latter approach shown to be more effective for psychological difficulties (Pinquart \& Sörensen, 2006; Gallagher-Thompson and Coon, 2007; Elvish et al., 2013). CBT is a psychological intervention with growing global empirical support for DCs, particularly with regards to depression outcomes (Kwon et al., 2017). It has been suggested that CBT alters negative caregiving related appraisals, reduces the use of unhelpful coping strategies and encourages caregivers to engage in positive activities (Laidlaw, 2015).

However, CBT can be a resource-intense intervention. Specific higher-education qualifications are usually required to license a therapist to deliver CBT, though the exact requirements are dependent upon the country in which it is being delivered (BABCP, 2012; NACBT, 2016). A recent review conducted by Kwon et al. (2017) reported the number of CBT sessions delivered for DCs ranged from 8 to 13 sessions, and such a number of sessions could be described as resource intense when delivered by accredited/licensed therapists. Less developed and poorly funded countries have less access to licensed health professionals, and are therefore less able to provide resourceintense psychological interventions such as high-intensity CBT (World Health Organization, 2014). Conversely, these are the areas which are likely to experience a greater demand for informal care. However, it remains yet to be determined if 'lowerintensity' CBT interventions are effective in reducing the psychological difficulties associated with dementia caregiving.

Low-intensity CBT interventions are those which are based on CognitiveBehavioural theory and are either not facilitated (e.g. CBT self-help), are facilitated by non-highly qualified facilitators, or are facilitated by highly qualified facilitators for only a 
short duration (Bennett-Levy et al., 2010). Low-intensity CBT-based interventions have gained support in the United Kingdom as part of a 'stepped-care' model of public health (NICE, 2011). The stepped-care model stipulates that the most effective, yet least resource intensive intervention should first be delivered before 'stepping-up' to a higher level of intensity (Bennett-Levy et al., 2010). It not clear if adopting such an approach is beneficial to DCs experiencing psychological difficulties as previous reviews of CBT for DCs do not consider the intensity of interventions.

Given the above mentioned limitations in resources, it is important to assess the effectiveness of low-intensity CBT for DCs on a range of relevant outcomes (Schulz, et al., 2002). Therefore, this study aims to examine the effectiveness of low-intensity CBTbased interventions for DCs on four primary outcomes of anxiety, depression, burden, and distress (defined as perceived stress or strain).

\section{Method}

\section{Protocol and Registration}

The review protocol was published on the PROSPERO international prospective register of systematic reviews (registration number: CRD42017060105; accessed via www.crd.york.ac.uk/PROSPERO).

\section{Search Strategy}

A systematic search of published literature was conducted using the electronic databases PsycINFO, MEDLINE, CINAHL and Scopus. A search of unpublished literature was conducted to address potential publication bias, using Open Grey, ProQuest. the ISRCTN registry and ClinicalTrials.gov. Reference lists of key review papers were hand searched. Key search terms included (a) dementia, (b) caregivers, (c) CBT-based therapy, (d) clinical trials, and related terms. Terms and limits were adapted to each source (see appendix A1 published as supplementary material online attached to the electronic version 
of this paper at https://www.cambridge.org/core/journals/international-psychogeriatrics).

Sources were searched from the date of database inception to July $1^{\text {st }} 2017$.

\section{Eligibility Criteria}

Articles were eligible if the following criteria were met: (a) Participants were informal adult caregivers for a person with an organic progressive dementia illness. (b) The intervention was based on CBT theory or techniques (Beck, 1979). For example, problem solving, thought challenging, behavioural activation, graded exposure etc. (Beck, 2011). Eligible CBT-based interventions included CBT psychoeducation, CBT therapy, multicomponent CBT-based interventions and third-wave CBT interventions, such as Acceptance and Commitment Therapy. (c) The intervention was low-intensity, as based on a public health stepped-care model for anxiety and depression, and existing review literature on low-intensity interventions, due to a lack of a universal definition (NICE, 2009, 2011a, 2011b; Richards et al., 2010; Rodgers et al., 2012).This was defined as interventions delivered by facilitators locally licensed/accredited to practice CBT independently, lasting no more than six hours; interventions delivered by facilitators who are not licensed/accredited to practice CBT independently, lasting any duration; and self-help interventions. Interventions with mixed accredited/licensed and non-accredited/licensed facilitators were included if the accredited/licensed facilitation did not exceed 6 hours. (d) The study reported outcomes for at least one of the four outcomes of interest: anxiety, depression, burden and distress. Distress was defined as perceived stress or strain, as described by Cohen (1983), and burden followed the description provided by Zarit (1980). (e) The study was a randomized controlled trial (RCT) or controlled clinical trial (CCT) using a waitlist, treatment as usual, placebo, or non-active intervention comparison group. Non-active interventions were defined as: (i) Interventions which are expected to have no effect on the outcome variables, based on prior research or theory. (ii) Interventions designed to be similar to treatment as usual. (iii) Interventions which match the treatment intervention in all aspects except for the expected 
CBT based active component, which must be replaced by a known non-active component (Karlsson and Bergmark, 2015).

\section{Study Selection}

The primary reviewer (LK) identified potentially relevant articles found in the search based on the abstracts. Duplicates were excluded and full reports of the remaining articles were obtained and assessed for eligibility by LK and the secondary reviewer (NK). Discrepancies were discussed and resolved, and a third reviewer was available for consultation if unresolved. Additional information was requested from authors of 27 articles where information was insufficient to determine eligibility. Missing information related to intervention intensity and frequently included facilitator profession/qualification level. Articles were subsequently excluded if additional information was not provided prior to data extraction (Figure 1).

\section{Quality Assessment \& Risk of Bias}

The quality and risk of bias of eligible studies was assessed using the RCT Psychotherapy Quality Rating Scale (RCT PQRS) which was adapted to reflect important qualities for low-intensity DC intervention RCTs (Kocsis et al., 2010). The scale rates the quality of studies based on the description of participants, definition and delivery of the intervention, outcome measures, data analysis, intervention assignment and overall study quality. Consideration of selection, detection, and attrition bias are included within these areas. The adapted RCT PQRS was a 27 item electronic spreadsheet scale, items relating to facilitation were omitted for self-help interventions. The scale included the addition of participant items relating to both the caregiver and cared for person, and an additional outcome item assessing the inclusion of measures of social acceptability and social validity as recommended by Schulz et al. (2002). The completed scale provided a quality percentage score and one of seven qualitative classification descriptors ranging from exceptionally poor to exceptionally good. Studies which were rated as 'very poor' (16 to 
$29 \%$ ) or 'exceptionally poor' ( $\leq 15 \%)$ were excluded. The adapted RCT PQRS was piloted by

LK and NK. The scale was then completed independently for all included studies by LK and an additional reviewer (AS), and any discrepancies were discussed and resolved.

Unresolved discrepancies were discussed with the third reviewer (NK) and resolved.

\section{Data Extraction}

An electronic data extraction form was used to extract study characteristics, participant information, intervention and control group characteristics and continuous outcome data, as per Cochrane guidelines (Higgins and Green, 2011). The data extraction form was piloted by LK and NK. Data was then extracted independently by LK and AS, and any discrepancies were discussed and referred to NK if not resolved. Missing outcome data was sought from authors and studies were excluded from quantitative analysis if data was not obtained. Five studies had missing data, two of which were subsequently excluded due to being unable to obtain data from authors (Figure 1).

\section{Statistical Analysis}

Statistical analyses were performed using Comprehensive Meta-Analysis software (Biostat Inc., 2014). The analyses used pre and post means (M), standard deviations (SD), and participant numbers $(\mathrm{N})$ for intervention and control groups for each study. Data from studies with multiple eligible intervention conditions were treated as individual studies when independent control groups were used (Borenstein et al., 2009). Studies containing multiple eligible intervention conditions that were compared to a single control group were merged to create a composite study to address statistical dependence (Scammacca et al., 2014). Composite data was derived by calculating an overall $\mathrm{M}$ across intervention conditions, and a composite SD was determined using a reverse analysis of variance method (Borenstein et al., 2009).

Separate meta-analyses were conducted for each of the four primary outcome variables. The Standardised Mean Difference (SMD) was calculated as Hedges' $g$ for study 
outcomes to allow for the use of different instruments across studies (Higgins and Green,

2011). The pooled intervention effect estimate was calculated using a random-effects model, as this is most appropriate model when there is expected variation in intervention characteristics (Borenstein et al., 2009; Higgins and Green, 2011; Cuijpers, 2016).

Heterogeneity was examined visually using a forest plot and outliers removed in sensitivity analysis. The $R^{2}$ statistic was calculated, which shows the percentage of the total variance which can be explained by heterogeneity (Cuijpers, 2016). Where there was evidence of heterogeneity of the treatment effect, subgroup analyses were conducted using intervention facilitation type (e.g. self-help, facilitated), delivery format (e.g. group, individual), delivery method (e.g. computerised, face-to-face), and intervention approach (e.g. CBT psychoeducation, CBT multi-component) as moderators. A random effects metaregression was planned to explore facilitator contact hours as a predictor of effect size.

Additional sensitivity analysis was conducted by excluding studies which appeared to meet the inclusion criteria but somewhat arbitrary or unclear compared to other included studies. Publication bias was explored visually using a funnel plot, and Orwin's Fail-safe N was calculated (Orwin, 1983; Borenstein et al., 2009). The 'trim and fill' method was applied to estimate effects sizes after bias had been taken into account (Duval et al., 2000).

\section{Results}

\section{Study Selection}

The search resulted in 12 eligible articles, with one article containing two eligible studies (Gallagher-Thompson et al., 2008), and another containing two eligible interventions using the same control group (Steffen, 2000). This resulted in a total of 14 eligible studies as presented in Figure 1. For the purposes of data analysis, the studies within GallagherThompson et al. (2008) were treated as individual studies (Gallagher-Thompson et al., 2008a; 2008b). The intervention groups contained within Steffen (2000) were treated as individual studies for descriptive purposes (Steffen, 2000a; 2000b), however outcome data 
from both intervention groups was merged to form composite scores for the purposes of quantitative analysis, due the use of a single control group (Borenstein et al., 2009).

\section{Study Characteristics}

Participant characteristics are summarised in Table 1. A total of 1131 participants were included in the analysis (602 intervention, 529 control), with mean ages ranging from 46.9 to 65.5 years. The majority were female spousal caregivers of people with any dementia or Alzheimer's disease. All samples were from developed countries, based on the Human Development Index (United Nations Development Programme, 2016).

Intervention characteristics are summarised in Table 2 . The majority of studies delivered multi-component CBT-based interventions, combining CBT techniques with other non-CBT techniques (e.g. 'identifying local resources' education) (Chang, 1999; Beauchamp et al., 2005; Gallagher-Thompson et al., 2008a; 2008b; Tremont et al., 2008; Au et al., 2010; Villareal-Reyna et al., 2012; Dowling et al., 2013; Kajiyama et al., 2013; Blom et al., 2015; Steffen and Gant, 2016). A minority of studies delivered interventions using only CBT-based techniques (Steffen, 2000a; 2000b; Chiu et al. 2015). There were no passive CBT-based psychoeducation only interventions, as all interventions contained active components, and no third-wave CBT-based interventions. One study identified as a CBT-based multicomponent intervention was selected for removal in sensitivity analysis due a minority of CBT-based components identified within the intervention (Dowling, et al., 2013).

Nine studies delivered individual interventions (Chang 1999; Steffen, 2000a; Beauchamp et al., 2005; Tremont et al., 2008; Dowling, et al., 2013; Kajiyama et al., 2013; Blom et al., 2015; Chui et al., 2015; Steffen and Grant, 2016) and five used a group method (Steffen, 2000b; Gallagher-Thompson et al., 2008a; 2008b; Au et al., 2010; Villareal-Reyna et al., 2012).

Delivery methods were wide ranging and included face-to face (Gallagher-Thompson et al. 2008a; 2008b; Villareal-Reyna et al., 2012; Au et al., 2015; Chui et al. 2015), face-to- 
face and video (Steffen, 2000a), face-to-face and videoconference (Dowling et al., 2013), telephone (Tremont et al., 2008), telephone and video (Chang, 1999; Steffen, 2000b), telephone, video and bibliotherapy (Steffen and Grant, 2016), computerised (Beauchamp et al., 2005; Blom et al., 2015), and computerised and bibliotherapy (Kajiyama et al., 2013). Nine studies were facilitated by non-CBT licensed facilitators (Chang, 1999; Steffen 2000a; 2000b; Gallagher-Thompson et al. 2008a; 2008b; Tremont et al., 2008; Au et al., 2012; Villareal-Reyna et al., 2012; Chui, 2015), two used mixed licensed and non-licensed facilitators (Dowling et al., 2013; Steffen and Grant, 2016), one used licensed facilitators (Blom et al., 2015) and two studies were non-facilitated self-help interventions (Beauchamp et al., 2005; Kajiyama et al. 2013). The total facilitator contact time ranged from 0 to 26 hours.

Control groups included non-active interventions (Chang, 1999; Gallagher-Thompson et al. 2008a; 2008b; Villareal-Reyna et al., 2012; Dowling et al., 2013; Kajiyama et al., 2013; Blom et al., 2015), waitlist controls (Steffen, 2000a; 2000b; Beauchamp et al., 2005; Au et al. 2010), and treatment as usual (Tremont et al., 2008; Chui et al., 2015; Steffen and Gant, 2016). Control and intervention group content overviews are provided in Table 3.

Of the 14 studies, five included anxiety outcomes (Chang, 1999; Beauchamp et al., 2005; Villareal-Reyna et al., 2012; Blom et al., 2015; Steffen and Grant, 2016), 12 included depression outcomes (Chang, 1999; Steffen, 2000a; 2000b; Beauchamp et al., 2005; Gallagher-Thompson et al. 2008a; 2008b; Tremont et al., 2008; Au et al., 2012; Dowling et al., 2013; Kajiyama et al., 2013; Blom et al., 2015; Steffen and Grant, 2016) three included burden outcomes (Tremont et al., 2008; Dowling et al., 2013; Chiu et al., 2015) and six included distress as an outcome (Beauchamp et al., 2005; Gallagher-Thompson et al., 2008a; 2008b; Dowling et al., 2013; Kajiyama et al., 2013; Chiu et al., 2015).

\section{Study Quality and Risk of Bias}


The quality of included studies presented in Table 4 ranged from 'moderately poor' to 'moderately good'. Four studies were rated as 'moderately poor' (Chang, 1999; Beauchamp et al., 2005; Au et al., 2010; Dowling et al., 2013), eight were rated as 'average' (Steffen 2000a; 2000b; Gallagher-Thompson et al., 2008a; 2008b; Tremont et al., 2008; VillarealReyna et al., 2012; Blom et al., 2015; Chiu et al., 2015), and two were rated as 'moderately good' (Kajiyama et al., 2013; Steffen and Grant, 2016).

There were few large scale RCTs and the majority of studies were pilot or feasibility RCTs (Steffen, 2000a; 2000b; Tremont et al., 2008; Au et al., 2012; Villareal-Reyna et al., 2012; Dowling et al., 2013; Chiu et al., 2015; Steffen and Grant 2016).

Furthermore, few studies reported follow-up data. Three studies reported follow-up data at one-month post intervention completion (Chang, 1999; Villareal-Reyna et al., 2012; Dowling et al., 2013), two reported two-month follow-up outcomes (Gallagher-Thompson et al., 2008a; 2008b) and only one reported six-month follow-up data (Steffen and Grant, 2016) Therefore, it was only possible to calculate pre-post effects sizes, and not follow-up effects sizes.

\section{Effect of Low-intensity CBT-based Interventions on Anxiety}

Five studies evaluated the effect of a low-intensity CBT-based intervention on anxiety (Chang 1999; Beauchamp et al., 2005; Villareal-Reyna et al., 2012; Blom et al., 2015; Steffen and Grant, 2016). All studies used differing tools to measure anxiety, including the state subscale of the State-Trait Anxiety Inventory (STAI-S) (Spielberger et al., 1970; Beauchamp et al., 2005), the anxiety subscales of the Hospital Anxiety and Depression Scale (HADS-A) (Zigmond and Snaith, 1983; Blom et al., 2015), the Brief Symptom Inventory (BSI) (Derogatis, 1993; Chang, 1999) and the Multiple Affect Adjective Check-list Revised (MAACL-R-A) (Lubin and Zuckerman, 1985; Steffen and Gant, 2016), and the Inventory of State Anxiety (ISA) (Spielberger and Diaz-Guerrero, 2002; Villareal-Reyna et al., 2012). 
The individual study effects sizes as Hedge's $g$ ranged from $0.25(95 \% \mathrm{Cl}-0.23$ to $0.73, p=0.31)$ to $2.74(95 \% \mathrm{Cl} 1.62$ to $3.86, p<0.01)$. In meta-analysis, there was a significant reduction of anxiety yielding a pooled effect size of $0.58(95 \% \mathrm{Cl} 0.17$ to $0.97, p<0.01)$ (see appendix A2 published as supplementary material online attached to the electronic version of this paper at https://www.cambridge.org/core/journals/international-psychogeriatrics). Statistically significant heterogeneity was found between studies $\left(I^{2}=78.82 \% p<0.01\right)$, and examination of the forest plot identified Villareal-Reyna et al. (2012) as an outlier. Exclusion of Villareal-Reyna et al. (2012) yielded a pooled effect size of 0.35 (95\% Cl 0.20 to 0.50 , $p<0.01)$, with no statistically significant heterogeneity $\left(I^{2}=0.00 \% p<0.62\right)$. Visual inspection of the funnel plot did not reveal publication bias (see appendix A3 published as supplementary material online attached to the electronic version of this paper at https://www.cambridge.org/core/journals/international-psychogeriatrics). Duval and Tweedie's (2000) trim and fill method did not impute any additional studies. Orwin's (1983) fail-safe $\mathrm{N}$ calculated 137 missing studies would be required to reduce Hedge's $g$ to under 0.01 .

\section{Effect of Low-intensity CBT-based Interventions on Depression}

Twelve studies evaluated the effect of a low-intensity CBT-based intervention on depression. Six studies used the Center for Epidemiological Studies Depression Scale (CES-D) (Gallagher-Thompson et al., 2008a; 2008b; Au et al., 2010; Dowling et al., 2013; Kajiyama et al., 2013; Blom et al. 2015), three used the Beck Depression Inventory (BDI) (Steffen, 2000a; 2000b; Beauchamp et al., 2005), one used the BDI-Il (Steffen and Grant, 2016), one used the Depression subscale of the Brief Symptom Inventory (BSI-D) (Chang, 1999), and one used the Geriatric Depression Scale (GDS) (Tremont et al., 2008).

Data from Steffen (2000a) and Steffen (2000b) was analysed as a single composite study (Steffen, 2000), as described above, yielding a total of eleven studies used in the analysis. The individual study effects sizes as Hedge's $g$ ranged from $0.17(95 \% \mathrm{Cl}-0.24$ to $0.59, p=0.41)$ to $0.74(95 \% \mathrm{Cl}-0.05$ to $1.54, p=0.07)$. In meta-analysis, there was a 
significant reduction of depression. The pooled effect size was 0.27 ( $95 \% \mathrm{Cl} 0.15$ to 0.39 , $p<0.01$ ) (see appendix A2 published as supplementary material online attached to the electronic version of this paper at https://www.cambridge.org/core/journals/internationalpsychogeriatrics). The exclusion of Dowling et al. (2013) in sensitivity analysis did not alter the overall effect size $(g=0.27,95 \% \mathrm{Cl} 0.15$ to $0.40, p>0.01)$ and hence it was not removed. There was no statistically significant heterogeneity found between studies $\left(I^{2}=0 \% p=0.98\right)$.

Visual inspection of the funnel plot suggested possible publication bias (Appendix $L$ ). Duval and Tweedie's (2000) trim and fill method imputed one study estimating an adjusted Hedge's $g$ of 0.26 (95\% Cl 0.14 to 0.38$)$. Orwin's (1983) fail-safe $\mathrm{N}$ calculated 283 missing studies would be required to reduce Hedge's $g$ to under 0.01 .

\section{Effect of Low-intensity CBT-based Interventions on Burden}

Three studies evaluated the effect of a low-intensity CBT-based intervention on burden (Tremont et al., 2008; Dowling et al., 2013; Chiu et al., 2015), using the Zarit Burden Interview (ZBI) (Zarit et al., 1980). The individual study effects sizes as Hedge's g ranged from $0.32(95 \% \mathrm{Cl}-0.21$ to $0.85, p=0.24)$ to $0.84(95 \% \mathrm{Cl} 0.15$ to $1.54, p=0.02)$. In metaanalysis, there was a significant reduction of burden as measured by the ZBI. The pooled effect size was 0.53 (95\% Cl 0.16 to $0.90, p=0.01$ ) (see appendix A2 published as supplementary material online attached to the electronic version of this paper at https://www.cambridge.org/core/journals/international-psychogeriatrics). The exclusion of Dowling et al. (2013) in sensitivity analysis did not alter the overall effect size $(g=0.53,95 \%$ $\mathrm{Cl} 0.02$ to $1.03, p=0.04$ ) and hence it was not removed. There was no statistically significant heterogeneity found between studies $\left(I^{2}=0 \% p=0.49\right)$.

Visual inspection of the funnel plot suggested possible publication bias (see appendix A3 published as supplementary material online attached to the electronic version of this paper at https://www.cambridge.org/core/journals/international-psychogeriatrics). Duval and Tweedie's (2000) trim and fill method imputed two studies estimating an adjusted Hedge's g 
of $0.32(95 \% \mathrm{Cl}-0.04$ to 0.67$)$. Orwin's (1983) fail-safe $\mathrm{N}$ calculated 156 missing studies would be required to reduce Hedge's g to under 0.01 .

\section{Effect of Low-intensity CBT-based Interventions on Distress}

Five studies evaluated the effect of a low-intensity CBT-based intervention on distress (Beauchamp et al., 2005; Gallagher-Thompson et al., 2008a; 2008b; Chiu et al., 2015; Dowling et al., 2013). The Caregiver Strain Instrument (CSI) (Bass et al., 1998) was used by Beauchamp et al. (2005). All other studies used the Perceived Stress Scale (PSS) (Cohen and Williamson, 1988; Gallagher-Thompson et al., 2008a; 2008b; Dowling et al., 2013; Chiu et al., 2015).

The individual study effects sizes as Hedge's $g$ ranged from $0.23(95 \% \mathrm{Cl} 0.00$ to $0.46, p=0.05)$ to $1.01(95 \% \mathrm{Cl} 0.18$ to $1.83, p=0.02)$. In meta-analysis, there was a significant reduction of distress yielding a pooled effect size of $0.33(95 \% \mathrm{Cl} 0.17$ to $0.48, p<0.01)$ (see appendix A2 published as supplementary material online attached to the electronic version of this paper at https://www.cambridge.org/core/journals/international-psychogeriatrics). A sensitivity analysis was conducted excluding Dowling et al. (2013), which resulted in a comparable pooled effect of $0.30(95 \% \mathrm{Cl} 0.15$ to $0.46, p=<0.01)$, and hence it was not removed. There was no statistically significant heterogeneity found between studies $\left(r^{2}=0.00 \% p=0.50\right)$.

Visual inspection of the funnel plot suggested possible publication bias (see appendix A3 published as supplementary material online attached to the electronic version of this paper at https://www.cambridge.org/core/journals/international-psychogeriatrics). Duval and Tweedie's (2000) trim and fill method imputed two studies estimating an adjusted Hedge's g of 0.29 (95\% Cl 0.12 to 0.46$)$. Orwin's (1983) fail-safe $\mathrm{N}$ calculated 190 missing studies would be required to reduce Hedge's g to under 0.01 . 


\section{Discussion}

Caring for a person with dementia has a psychological impact on informal caregivers. The number of informal DCs is expected to rise and resources offering support are limited, particularly in less developed countries. CBT is an intervention which has shown some promise in reducing psychological difficulties in DCs, however CBT can be resource intense. This study reviewed the effectiveness of low-intensity CBT-based interventions for informal DCs on the outcomes of anxiety, depression, burden and distress (stress/strain) compared to control conditions. Significant intervention effects were obtained for all psychological outcome variables, however the size of the effects varied across outcomes. Heterogeneity was low for all meta-analyses, though it is possible that the small number of studies did not allow for heterogeneity detection (Cuijpers, 2006). Possible publication bias was identified for depression, burden, and distress analyses, though adjusted effects sizes are not discussed as publication bias assessment is unreliable when less than 30 studies are included (Cuijpers, 2016).

\section{Anxiety}

Only five studies were included in the meta-analysis of anxiety outcomes, which is consistent with observations that anxiety is somewhat neglected in DC intervention literature (Schulz et al., 2002; Li et al., 2013). The overall effect of low-intensity CBT-based interventions on reducing anxiety was moderate with a Hedge's $g$ of 0.58 . This was reduced to a small effect of 0.35 following the exclusion of Villareal-Reyna et al. (2012) as an outlier. Villareal-Reyna et al. (2012) involved the greatest number of facilitator contact hours and was the only study which employed a group-based intervention which reported on anxiety. It is possible that factors such as increased facilitator contact time, and contact with other DCs in the group setting may have resulted in a greater intervention effect, however further research would be required to explore these hypotheses.

\section{Depression}


An overall reduction in depression was found with a small effect size of 0.27 pooled across the twelve included studies. The obtained effect is smaller than reports of the effect of CBT for DCs when not restricted to low-intensity (Kwon et al., 2017). It could be argued that low-intensity CBT-based interventions may only be beneficial for DCs with low levels of depression, and the studies included in this meta-analysis did not place limits on participant depression levels. However, in a non-caregiver population, participants with more severe depression do not benefit less from low-intensity interventions than those with milder depression (Bower et al., 2013). It is therefore important for future research to examine which aspects of low-intensity CBT-based interventions have the greatest impact on depression outcomes.

\section{Burden}

Low-intensity CBT-based interventions were shown to reduce burden outcomes with a moderate effect size of 0.53 . However only three studies were included in the analysis and as such results should be interpreted with caution. Although burden is not a clinical diagnosis, it is unexpected that so few studies examined burden, given reports of high levels of burden in DCs (Brodaty et al., 2014; Liu et al., 2017). It has been suggested that some burden predictor variables (e.g. person with dementia characteristics, care situation) are mediated by DC appraisals (Sörensen and Conwell, 2011). Given that low-intensity CBTbased interventions often target DC appraisals; it would be beneficial for future low-intensity CBT-based studies to include burden as an outcome.

\section{Distress}

An overall reduction in distress, defined as perceived stress or strain, was found across the five included studies with a small effect size of 0.33 , though results should be interpreted with caution due to the small number of studies. The small number of studies was unexpected given that distress is commonly reported on in the DC literature. However, 'distress' is often used an umbrella term to refer to the other variables examined in this paper 
18

(i.e. anxiety, depression and burden) (Ferrara et al., 2008; Cress, 2009). Therefore, labelling outcomes as 'distress' should be avoided to prevent ambiguity, and the use of this term can be considered a limitation of this paper.

Nonetheless, it is recommended that future DC intervention studies should include stress/strain as an outcome, particularly as it has been suggested that stress/strain may mediate psychological morbidity (Schulz and Martire, 2004).

\section{Strengths and limitations}

A strength of this study is the rigorous selection strategy, and use of a clear definition for 'low-intensity'. However, the latter may also be considered a limitation, as there is no universal agreement regarding defining interventions as low-intensity. The examination of multiple outcomes is a strength, though this limited the depth of discussion for each outcome. Furthermore, it is important to note there are additional relevant DCs outcomes which were not included (e.g. life satisfaction) (Thomas et al., 2006).

The small number of studies included in each meta-analysis created several limitations. Firstly, it may not have been possible to detect heterogeneity even if it existed (Cuijpers, 2016). As such, the impact of intervention characteristic moderators was not examined. Given the variety in intervention characteristics of included studies (e.g. intervention components, facilitators, delivery format etc.), it is not possible to conclude which low-intensity CBT-based interventions are most beneficial, how they should be delivered and by whom. Secondly, most studies recruited caregivers for people with Alzheimer's dementia, or did not specify dementia type. Therefore, it cannot be determined if low-intensity CBT is effective for caregivers of different dementia illnesses, as some types of dementia present with more behavioural problems which could lead to increased caregiver psychological difficulties (Riedijk et al., 2006). Furthermore, all included studies used samples from developed countries. This limits the generalisation of results to less developed countries. Caregivers in such areas are reported to have less knowledge of dementia, less 
formal support, greater financial difficulty and differing cultural needs (Kalula and Petros, 2011). It is not known if this combination of factors would alter the effectiveness of lowintensity CBT-based interventions.

\section{Research Implications}

This study highlights the requirement for larger scale low-intensity CBT-based intervention studies, using participant samples from both developed and less developed countries, reporting on a variety of outcomes relevant to DCs. The inclusion of long-term follow-up outcomes will help determine if effects for DCs are long lasting, or time limited, as has been suggested for low-intensity CBT-based interventions in other clinical populations (Ali et al., 2017). Further research should aim to identify important characteristics of lowintensity CBT-based interventions which moderate outcomes, to aid the development of future interventions. It is also important that future studies report information about the profession and qualifications of intervention facilitators to support this process, as this review identified such details were frequently absent and required clarification from authors.

\section{Clinical implications}

Despite the above limitations, this study provides support for the use of low-intensity CBT-based interventions for DCs. The expected increase in the need for informal dementia care is likely to have a greater impact on DCs residing in areas where resources are limited. Therefore, a small or medium reduction in the psychological difficulties experienced by DCs is an important reduction, particularly when a smaller amount resources are expended to achieve such an effect. This study also provides support for further exploration into a stepped-care approach for DCs.

\section{Conclusions}

This study shows that low-intensity CBT-based interventions reduce levels of anxiety, depression, burden and distress (stress/strain) experienced by DCs, when compared to nonactive controls. However, more research is required to increase the generalisability of 


\section{CAREGIVERS}

findings to the poorly resourced populations which may benefit the most. Furthermore,

additional exploration into the most important aspects of low-intensity CBT-based

interventions is necessary to guide intervention development to increase effectiveness. 
Conflicts of Interest

None.

\section{Description of Author Roles}

L. Kaddour designed the study, extracted and quality assessed data, conducted statistical analysis and wrote the article. A. Schaller extracted and quality assessed data, and resolved discrepancies with L. Kaddour. Dr N. Kishita supervised the study design, data extraction and the writing of the article.

\section{Acknowledgements}

The contribution of authors who provided additional information for the assessment of study eligibility is acknowledged. 


\section{References}

Ali, S. et al. (2017) 'How durable is the effect of low intensity CBT for depression and anxiety? Remission and relapse in a longitudinal cohort study', Behaviour Research and Therapy, 94, pp. 1-8. doi: 10.1016/j.brat.2017.04.006.

Au, A. et al. (2010) 'The Coping with Caregiving Group Program for Chinese caregivers of patients with Alzheimer's disease in Hong Kong.', Patient Education And Counseling. Department of Applied Social Science, The Hong Kong Polytechnic University, Hung Hom, Hong Kong, China. ssalma@inet.polyu.edu.hk: Elsevier, 78(2), pp. 256-260. doi: 10.1016/j.pec.2009.06.005.

BABCP (2012) BABCP MINIMUM TRAINING STANDARDS. Available at:

http://www.babcp.com/files/Minimum-training-standards-V6-0413.pdf (Accessed: 27 December 2017).

Bass, D. M. et al. (1998) 'The buffering effect of a computer support network on caregiver strain', Journal of Aging and Health. doi: 10.1177/089826439801000102.

Beauchamp, N. et al. (2005) 'Worksite-Based Internet Multimedia Program for Family Caregivers of Persons With Dementia', The Gerontologist. Oxford University Press, 45(6), pp. 793-801. doi: 10.1093/geront/45.6.793.

Beck (2011) Cognitive behavior therapy: Basics and beyond, Cognitive behavior therapy: Basics and beyond (2nd ed.).

Beck, A. T. (1979) Cognitive therapy of depression, Cognitive Therapy of Depression. Bennett-Levy, J. et al. (2010) 'Low intensity CBT interventions: a revolution in mental health care', in Oxford Guide to Low Intensity CBT Interventions. doi:

10.1093/med:psych/9780199590117.003.0001.

Bennett, J. M., Fagundes, C. P. and Kiecolt-Glaser, J. K. (2013) 'The Chronic Stress of Caregiving Accelerates the Natural Aging of the Immune System', in Immunosenescence. New York, NY: Springer New York, pp. 35-46. doi: 10.1007/978-1-4614-4776-4_3.

Bertrand, R. M., Fredman, L. and Saczynski, J. (2006) 'Are all caregivers created equal? 
Stress in caregivers to adults with and without dementia', Journal of Aging and Health. doi: 10.1177/0898264306289620.

Biostat Inc. (2014) Comprehensive Meta-Analysis Software (CMA). Available at: https://www.meta-analysis.com/index.php?cart=B5T5990373 (Accessed: 27 December 2017).

Blom, M. M. et al. (2015) 'Effectiveness of an Internet Intervention for Family Caregivers of People with Dementia: Results of a Randomized Controlled Trial', PLOS ONE. Edited by N. Walker, 10(2), p. e0116622. doi: 10.1371/journal.pone.0116622.

Borenstein, M. et al. (2009) Introduction to Meta-Analysis. Chichester, UK: John Wiley \& Sons, Ltd. doi: 10.1002/9780470743386.

Bower, P. et al. (2013) 'Influence of initial severity of depression on effectiveness of low intensity interventions: meta-analysis of individual patient data.', BMJ (Clinical research ed.). Centre for Reviews and Dissemination (UK), 346, p. f540. Available at: http://www.ncbi.nlm.nih.gov/pubmed/23444423 (Accessed: 23 January 2018). Brodaty, H. et al. (2014) 'Prevalence and Predictors of Burden in Caregivers of People with Dementia', The American Journal of Geriatric Psychiatry, 22(8), pp. 756-765. doi: 10.1016/j.jagp.2013.05.004.

Brodaty, H. and Donkin, M. (2009) 'Family caregivers of people with dementia', Dialogues in Clinical Neuroscience. doi: 10.1002/gps.

Chang, B. L. (1999) 'Cognitive-behavioral intervention for homebound caregivers of persons with dementia.', Nursing Research. US: Lippincott Williams \& Wilkins, 48(3), pp. 173-182. doi: 10.1097/00006199-199905000-00007.

Chiu, M. et al. (2015) ‘Evaluation of a problem-solving (PS) techniques-based intervention for informal carers of patients with dementia receiving in-home care.', International Psychogeriatrics. The Cyril and Dorothy,Joel and Jill Reitman Centre for Alzheimer's Support and Training,Mount Sinai Hospital,Toronto,Ontario,M5G 1X5,Canada.: Cambridge University Press, 27(6), pp. 937-948. doi: 10.1017/S1041610214002798. 
Cohen, S., Kamarck, T. and Mermelstein, R. (1983) 'A global measure of perceived stress', Journal of Health and Social Behaviour.

Cress, C. (2009) Handbook of Geriatric Care Management. Jones and Bartlett Publishers. Available at: http://www.jblearning.com/catalog/9781284078985/ (Accessed: 23 January 2018).

Cuijpers, P. (2016) Meta-analyses in mental health research . A practical guide. Vrije Universiteit Amsterdam.

Derogatis, L. R. (1993) BSI Brief Symptom Inventory: Administration, Scoring, and Procedure Manual , 4th Ed. doi: 10.1017/CBO9781107415324.004.

Dowling, G. A. et al. (2013) 'Life enhancing activities for family caregivers of people with frontotemporal dementia.', Alzheimer Disease And Associated Disorders. Departments of *Physiological Nursing $¥$ Osher Center for Integrative Medicine, University of California §Medicine †Memory and Aging Center, San Francisco, CA.: Lippincott Williams \& Wilkins, 28(2), pp. 175-181. doi: 10.1097/WAD.0b013e3182a6b905.

Duval, S. et al. (2000) 'Trim and fill: a simple funnel plot based method of testing and adjusting for publication bias in meta-analysis', Biometrics. doi: 10.1111/j.0006$341 x .2000 .00455 . x$.

Elvish, R. et al. (2013) 'Psychological interventions for carers of people with dementia: A systematic review of quantitative and qualitative evidence', Counselling and Psychotherapy Research, 13(2), pp. 106-125. doi: 10.1080/14733145.2012.739632.

Ferrara, M. et al. (2008) 'Prevalence of stress, anxiety and depression in with Alzheimer caregivers.', Health and quality of life outcomes. BioMed Central, 6, p. 93. doi: 10.1186/1477-7525-6-93.

Franca, C. (2017) Fix Dementia Care: funding. Alzheimer's Society. Available at: https://www.alzheimers.org.uk/info/20016/campaigns/1022/fix_dementia_care_funding (Accessed: 14 December 2017).

Friedman, E. M. et al. (2015) ‘US Prevalence And Predictors Of Informal Caregiving For 
Dementia.', Health affairs (Project Hope). NIH Public Access, 34(10), pp. 1637-41. doi: 10.1377/hlthaff.2015.0510.

Gallagher-Thompson, D. et al. (2008) 'Effectiveness of cognitive/behavioral small group intervention for reduction of depression and stress in non-Hispanic White and Hispanic/Latino women dementia family caregivers: Outcomes and mediators of change.', Journal of Rational-Emotive \& Cognitive-Behavior Therapy. Gallagher-Thompson, Dolores, Department of Psychiatry and Behavioral Sciences, Stanford University School of Medicine, Stanford, CA, US: Springer (Psychotherapy with older people), 26(4), pp. 286-303. doi: 10.1007/s10942-008-0087-4.

Gallagher-Thompson, D. and Coon, D. W. (2007) ‘Evidence-based psychological treatments for distress in family caregivers of older adults', Psychology and Aging. doi: 10.1037/08827974.22.1.37.

Higgins, J. and Green, S. (2011) 'Cochrane Handbook for Systematic Reviews of Interventions', Cochrane Handbook for Systematic Reviews of Interventions Version 5.1.0. Kajiyama, B. et al. (2013) 'Exploring the effectiveness of an Internet-based program for reducing caregiver distress using the iCare Stress Management e-Training Program', Aging \& Mental Health, 17(5), pp. 544-554. doi: 10.1080/13607863.2013.775641.

Kalula, S. and Petros, G. (2011) 'Responses to dementia in Less Developed Countries with a focus on South Africa', International Federaition of Aging: Global Ageing, 7(1), pp. 31-40. Karlsson, P. and Bergmark, A. (2015) 'Compared with what? An analysis of control-group types in Cochrane and Campbell reviews of psychosocial treatment efficacy with substance use disorders', Addiction. doi: 10.1111/add.12799.

Knapp, M. et al. (2007) 'Dementia UK’, Alzheimer’s Society.

Kocsis, J. H. et al. (2010) 'A new scale for assessing the quality of randomized clinical trials of psychotherapy', Comprehensive Psychiatry. Elsevier Inc., 51(3), pp. 319-324. doi: 10.1016/j.comppsych.2009.07.001.

Kwon, O.-Y. et al. (2017) 'Effectiveness of Cognitive Behavioral Therapy for caregivers of 
people with dementia: a systematic review and meta-analysis', Journal of Clinical Neurology, 13(4), p. 394. doi: 10.3988/jcn.2017.13.4.394.

Laidlaw, K. (2015) CBT for older people : an introduction. 1 edition. London: Sage Publications Ltd.

Li, R. et al. (2013) 'Do changes in coping style explain the effectiveness of interventions for psychological morbidity in family carers of people with dementia? A systematic review and meta-analysis', International Psychogeriatrics, 25(02), pp. 204-214. doi: 10.1017/S1041610212001755.

Liu, S. et al. (2017) 'Caregiver burden and prevalence of depression, anxiety and sleep disturbances in Alzheimer's disease caregivers in China', Journal of Clinical Nursing, 26(910), pp. 1291-1300. doi: 10.1111/jocn.13601.

Lubin, B. and Zuckerman, M. (1985) Manual for the MAACL-R: Multiple Affect Adjective Check List-Revised - Bernard Lubin, Marvin Zuckerman - Google Books. San Diego, CA: EdITS.

McKeith, I. and Cummings, J. (2005) 'Behavioural changes and psychological symptoms in dementia disorders', The Lancet Neurology. doi: http://dx.doi.org/10.1016/S14744422(05)70219-2.

NACBT (2016) Certifications: National Association of Cognitive-Behavioral Therapists. Available at: http://www.nacbt.org/certifications-htm/ (Accessed: 27 December 2017). National Institute for Health and Clinical Excellence (2009) Depression in Adults: Recognition and Management Clinical Guideline: NICE Guideline [CG90], National Collaborating Centre for Mental Health.

National Institute for Health and Clinical Excellence (2011) Generalised Anxiety Disorder and Panic Disorder in Adults: Management, National Institute for Health and Clinical Excellence. Orwin, R. G. (1983) 'A Fail-Safe N for Effect Size in Meta-Analysis', Journal of Educational Statistics. doi: 10.2307/1164923.

Pinquart, M. and Sörensen, S. (2006) 'Helping caregivers of persons with dementia: Which 
interventions work and how large are their effects?', International Psychogeriatrics. doi: 10.1017/S1041610206003462.

Prince, M. et al. (2013) 'The global prevalence of dementia: A systematic review and metaanalysis', Alzheimer's \& Dementia. Elsevier, 9(1), p. 63-75.e2. doi:

10.1016/J.JALZ.2012.11.007.

Programme, U. N. D. (2016) Human Development Report 2016 Human Development for Everyone. Available at:

hdr.undp.org/sites/default/files/2016_human_development_report.pdf.

Richards, D.A., Weaver, A., Utley, M., Bower, P., Cape, J., Gallivan, S., ... Vasilakis, C. (2010) Developing evidence based and acceptable stepped care systems in mental health care: an operational research project. Final report. NIHR Service Delivery and Organisation programme. Available at:

https://www.journalslibrary.nihr.ac.uk/programmes/hsdr/081504109/\#/ (Accessed: 19 January 2018).

Riedijk, S. R. et al. (2006) 'Caregiver burden, health-related quality of life and coping in dementia caregivers: A comparison of frontotemporal dementia and Alzheimer's disease', Dementia and Geriatric Cognitive Disorders. doi: 10.1159/000095750.

Rodgers, M. et al. (2012) 'The clinical effectiveness and cost-effectiveness of low-intensity psychological interventions for the secondary prevention of relapse after depression: A systematic review', Health Technology Assessment. doi: 10.3310/hta16280.

Scammacca, N., Roberts, G. and Stuebing, K. K. (2014) 'Meta-analysis with complex research designs: dealing with dependence from multiple measures and multiple group comparisons.', Review of educational research. NIH Public Access, 84(3), pp. 328-364. doi: $10.3102 / 0034654313500826$.

Schulz, R. et al. (1995) 'Psychiatric and physical morbidity effects of dementia caregiving: Prevalence, correlates, and causes', Gerontologist. doi: 10.1093/geront/35.6.771.

Schulz, R. et al. (2002) 'Dementia caregiver intervention research: in search of clinical 
significance', The Gerontologist. Oxford University Press, 42(5), pp. 589-602. doi:

10.1093/geront/42.5.589.

Schulz, R. and Martire, L. M. (2004) 'Family caregiving of persons with dementia:

prevalence, health effects, and support strategies', The American Journal of Geriatric Psychiatry. doi: 10.1097/00019442-200405000-00002.

Sörensen, S. and Conwell, Y. (2011) 'Issues in dementia caregiving: effects on mental and physical health, intervention strategies, and research needs.', The American journal of geriatric psychiatry : official journal of the American Association for Geriatric Psychiatry. NIH Public Access, 19(6), pp. 491-6. doi: 10.1097/JGP.0b013e31821c0e6e.

Spielberger, C. D. and Diaz-Guerrero, R. (2002) IDARE: Inventario de ansiedad: RasgoEstado [IDARE: inventory of anxiety]. México City, México: El Manual Moderno.

Spielberger, C. D., Gorsuch, R. L. and Lushene, R. E. (1970) 'Manual for the State-Trait Anxiety Inventory', Palo Alto, CA: Consulting Psychologists Press.

Steffen, A. M. (2000) 'Anger management for dementia caregivers: A preliminary study using video and telephone interventions', Behavior Therapy, 31(2), pp. 281-299. doi: 10.1016/S0005-7894(00)80016-7.

Steffen, A. M. and Gant, J. R. (2016) 'A telehealth behavioral coaching intervention for neurocognitive disorder family carers', International Journal of Geriatric Psychiatry, 31(2). doi: $10.1002 / g p s .4312$.

The National Institute for Health and Care Excellence (2011) Common mental health disorders: The NICE guideline on identification and pathways to care, The British Psychological Society and The Royal College of Psychiatrists. doi: clinical guideline CG123.2011.

Thomas, P. et al. (2006) 'Dementia patients caregivers quality of life: The PIXEL study', International Journal of Geriatric Psychiatry. doi: 10.1002/gps.1422.

Tremont, G. et al. (2008) 'Telephone-delivered psychosocial intervention reduces burden in dementia caregivers', Dementia, 7(4). doi: 10.1177/1471301208096632. 


\section{CAREGIVERS}

Villareal-Reyna, M. de los Á. et al. (2012) 'Outcomes of interventions for Alzheimer's family caregivers in Mexico.', Western Journal of Nursing Research. Universidad Autónoma de Coahuila, School of Nursing, Mexico: Sage Publications Inc., 34(7), pp. 973-990. doi: $10.1177 / 0193945910387283$.

World Health Organization (2012) ‘Dementia: a public health priority’, Dementia. doi: 97892 41564458.

World Health Organization (2014) '2014 Mental health atlas', Who. doi: 10.1037/e360882004-001.

Zarit, S. H., Reever, K. E. and Bach-Peterson, J. (1980) 'Relatives of the impaired elderly: Correlates of feelings of burden', Gerontologist. doi: 10.1093/geront/20.6.649.

Zigmond, a S. and Snaith, R. P. (1983) 'The hospital anxiety and depression scale (HADS).', Acta Psychiatrica Scandinavica. doi: 10.1016/S0016-5085(01)83173-5. 
Figure 1. Systematic literature search flow chart

Exclusion of articles not
meeting full inclusion
$\quad$ criteria ( $n=63$ )
Reasons for exclusion:
Not a 2-arm quantitative
intervention study ( $n=17)$
High-intensity intervention
( $n=13)$
Unable to obtain additional information from author ( $n$ = 10)

Active control condition ( $n$ = 8)

Not CBT-based ( $n=4)$

Feasibility study without outcome data $(n=3)$

Intervention with cared for person only ( $n=2)$

Unable to obtain full article $(n=1)$

No English translation of article $(n=2)$

Cared for person not confirmed to have dementia $(n=1)$

Review article $(n=1)$

Not exclusively dementia caregivers $(n=1)$
Systematic literature search:

$$
(N=819)
$$

Psyclnfo: 244

Medline: 258

Cinahl: 98

Scopus:53

ProQuest: 140

OpenGrey: 2

ISRCTN registry: 0

ClinicalTrials.gov: 2

Hand search: 22

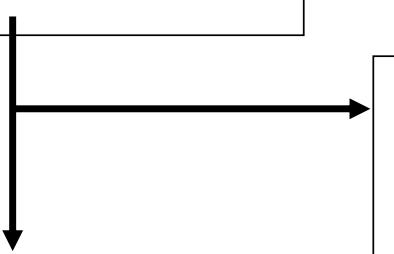

Exclusion of irrelevant articles based on title and

Potentially relevant articles selected on title or abstract $(n=128)$ abstract $(n=619)$

Exclusion of duplicates $(n=$ 51)

Articles selected for full eligibility assessment $(n=77)$

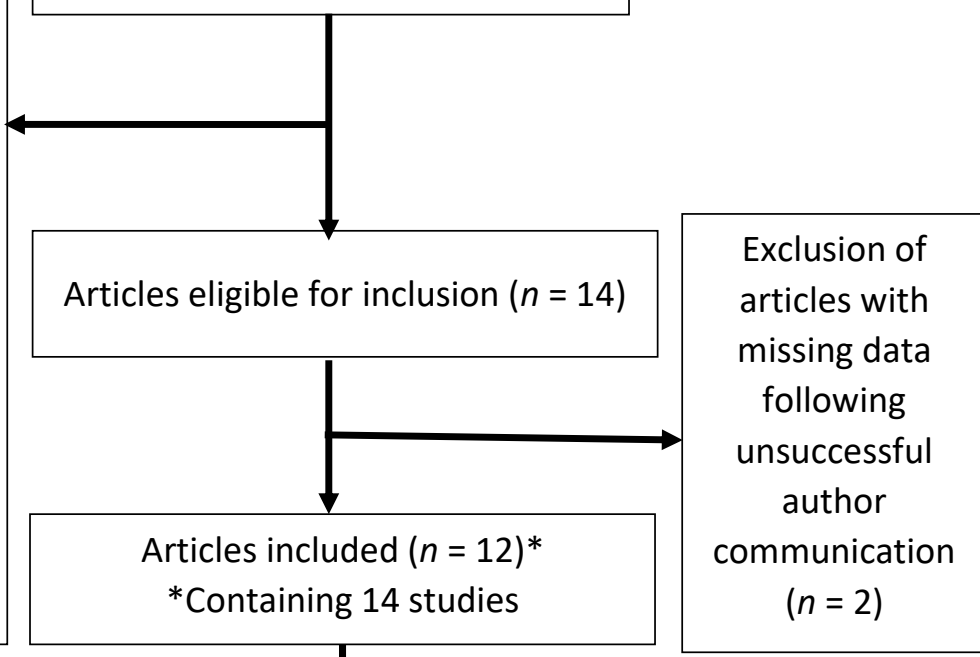

\begin{tabular}{|c|c|c|c|}
\hline \multicolumn{1}{l|}{} & \multicolumn{1}{c|}{$\downarrow$} \\
\hline $\begin{array}{c}\text { Studies with } \\
\text { Anxiety outcome } \\
(n=5)\end{array}$ & $\begin{array}{c}\text { Studies with } \\
\text { Depression } \\
\text { outcome }(n=12)\end{array}$ & $\begin{array}{c}\text { Studies with } \\
\text { Burden outcome } \\
(n=3)\end{array}$ & $\begin{array}{c}\text { Studies with } \\
\text { Distress outcome } \\
(n=6)\end{array}$ \\
\hline
\end{tabular}


Table 1. Participant characteristics and quality of studies included in the meta-analyses

\begin{tabular}{|c|c|c|c|c|c|c|c|c|}
\hline Study ID & Country & $\mathbf{N}$ & $\begin{array}{l}\text { Mean } \\
\text { age } \\
\text { (SD) }\end{array}$ & Ethnicity (\%) & $\begin{array}{l}\% \\
\text { female }\end{array}$ & $\begin{array}{l}\text { Relationship to } \\
\text { care recipient (\%) }\end{array}$ & $\begin{array}{l}\text { Care recipient } \\
\text { dementia type } \\
(\%)\end{array}$ & $\begin{array}{l}\text { Study } \\
\text { quality (\% } \\
\text { score) }\end{array}$ \\
\hline $\begin{array}{l}\text { Au et al. } \\
(2010)\end{array}$ & China & 27 & NR & $\begin{array}{l}\text { Chinese Cantonese } \\
(100)\end{array}$ & 100 & $\begin{array}{l}\text { Spouse (NR); } \\
\text { Adult child (NR) }\end{array}$ & Alzheimer's & $\begin{array}{l}\text { Moderately } \\
\text { poor (40.7) }\end{array}$ \\
\hline $\begin{array}{l}\text { Beauchamp } \\
\text { et al. (2005) }\end{array}$ & USA & 299 & $\begin{array}{l}46.9 \\
(12.2)\end{array}$ & $\begin{array}{l}\text { Caucasian (88); } \\
\text { African-American (4); } \\
\text { Hispanic (8); Other (8) }\end{array}$ & 73 & $\begin{array}{l}\text { Adult child }(67) ; \\
\text { Other relative (23); } \\
\text { Spouse }(7) ; \text { Non- } \\
\text { relative (3) }\end{array}$ & Any dementia & $\begin{array}{l}\text { Moderately } \\
\text { poor (34.7) }\end{array}$ \\
\hline $\begin{array}{l}\text { Blom et al. } \\
(2015)\end{array}$ & Netherlands & 245 & $\begin{array}{l}61.2 \\
(12.37)\end{array}$ & Dutch (99.2) & 69.4 & $\begin{array}{l}\text { Spouse (58.4); } \\
\text { Adult child (39.6) }\end{array}$ & $\begin{array}{l}\text { Alzheimer's } \\
\text { (74.5); Any } \\
\text { dementia }\end{array}$ & $\begin{array}{l}\text { Average } \\
(57.6)\end{array}$ \\
\hline $\begin{array}{l}\text { Chang } \\
(1999)\end{array}$ & USA & 65 & $\begin{array}{l}66.5 \\
(\mathrm{NR})\end{array}$ & $\begin{array}{l}\text { Caucasian (79.1); } \\
\text { African-American (16.3) }\end{array}$ & 100 & $\begin{array}{l}\text { Spouse (NR); } \\
\text { Adult child (NR) }\end{array}$ & Any dementia & $\begin{array}{l}\text { Moderately } \\
\text { poor (33.9) }\end{array}$ \\
\hline $\begin{array}{l}\text { Chiu et al. } \\
\text { (2015) }\end{array}$ & Canada & 54 & NR & NR & 83 & $\begin{array}{l}\text { Spouse (NR); } \\
\text { Adult child (NR) }\end{array}$ & Any dementia & $\begin{array}{l}\text { Average } \\
(50.8)\end{array}$ \\
\hline $\begin{array}{l}\text { Dowling et } \\
\text { al (2013) }\end{array}$ & USA & 24 & $\begin{array}{l}59.5 \\
(8.1)\end{array}$ & $\begin{array}{l}\text { White (90), Hispanic \& } \\
\text { African-American (10) }\end{array}$ & 70.8 & $\begin{array}{l}\text { Spouse (87.5); } \\
\text { Other (NR) }\end{array}$ & Fronto-temporal & $\begin{array}{l}\text { Moderately } \\
\text { poor (35.6) }\end{array}$ \\
\hline
\end{tabular}


Gallagher-

Thompson

et al.

USA

$95 \quad 63.4$

White (100)

$100 \quad \begin{aligned} & \text { Spouse (NR); } \\ & \text { Adult child (NR) }\end{aligned}$

Any dementia

Average

(2008a)

\section{Gallagher- \\ Thompson}

et al.

USA

$89 \quad 51.45$

(2008b)

SA

$89 \quad(11.55)$

Hispanic/Latina (100)

100

Spouse (NR);
Adult child (NR)

Any dementia

Average

(54.2)

\begin{tabular}{|c|c|c|c|c|c|c|c|c|}
\hline $\begin{array}{l}\text { Kajiyama et } \\
\text { al. (2013) }\end{array}$ & USA & 103 & NR & $\begin{array}{l}\text { Caucasian (85); } \\
\text { African-American (2.9); } \\
\text { Asian-American (4.8); } \\
\text { Hispanic-American } \\
\text { (2.9); Native-American } \\
\text { (1.9); Hawaiian/Pacific } \\
\text { Islanders (0.9) }\end{array}$ & 83 & $\begin{array}{l}\text { Spouse (NR); } \\
\text { Adult child (NR); } \\
\text { Other (NR) }\end{array}$ & Any dementia & $\begin{array}{l}\text { Moderately } \\
\text { good } \\
(63.3)\end{array}$ \\
\hline $\begin{array}{l}\text { Steffen } \\
(2000)^{*}\end{array}$ & USA & 28 & $\begin{array}{l}64.06 \\
(11.5)\end{array}$ & $\begin{array}{l}\text { Caucasian (75.8); } \\
\text { African-American (24.2) }\end{array}$ & 75.8 & $\begin{array}{l}\text { Spouse (54.5); } \\
\text { Adult child (36.4); } \\
\text { Other (9.1) }\end{array}$ & $\begin{array}{l}\text { Alzheimer's } \\
\text { (84.8); Other } \\
\text { dementia (15.2) }\end{array}$ & $\begin{array}{l}\text { Average } \\
(45.8)\end{array}$ \\
\hline $\begin{array}{l}\text { Steffen and } \\
\text { Grant } \\
(2016)\end{array}$ & USA & 46 & $\begin{array}{l}60.3 \\
(10.8)\end{array}$ & $\begin{array}{l}\text { White (79.7); African- } \\
\text { American (20.3) }\end{array}$ & 100 & $\begin{array}{l}\text { Spouse (52); Adult } \\
\text { child (48) }\end{array}$ & $\begin{array}{l}\text { Alzheimer's } \\
\text { (62.2); Vascular } \\
\text { (8.1); Lewy-body } \\
\text { (2.7); Other } \\
\text { dementia }\end{array}$ & $\begin{array}{l}\text { Moderately } \\
\text { good } \\
(62.7)\end{array}$ \\
\hline
\end{tabular}




\begin{tabular}{|c|c|c|c|c|c|c|c|c|}
\hline $\begin{array}{l}\text { Tremont et } \\
\text { al. (2008) }\end{array}$ & USA & 33 & NR & NR & NR & $\begin{array}{l}\text { Spouse (33); Adult } \\
\text { child (21.7) }\end{array}$ & Any dementia & $\begin{array}{l}\text { Average } \\
(55.9)\end{array}$ \\
\hline $\begin{array}{l}\text { Villareal- } \\
\text { Reyna et al. } \\
(2012)\end{array}$ & Mexico & 23 & NR & NR & NR & $\begin{array}{l}\text { Adult child (NR); } \\
\text { Non-specified } \\
\text { family member } \\
\text { (NR) }\end{array}$ & Alzheimer's & $\begin{array}{l}\text { Average } \\
(54.2)\end{array}$ \\
\hline
\end{tabular}

Note. *Composite study combining Steffen 2000a \& 2000b; ${ }^{* *}$ Steffen 2000a; ${ }^{* *}$ Steffen 2000b; NR = Not reported. 
Table 2. Characteristics of interventions and outcome measures for each study

\begin{tabular}{|c|c|c|c|c|c|c|c|}
\hline Study ID & Approach & $\begin{array}{l}\text { Delivery } \\
\text { format }\end{array}$ & Delivery method & Facilitation type & $\begin{array}{l}\text { Total } \\
\text { facilitator } \\
\text { contact } \\
\text { time } \\
\text { (hours) }\end{array}$ & $\begin{array}{l}\text { Outcome } \\
\text { instruments }\end{array}$ & $\begin{array}{l}\text { Measurement } \\
\text { time points }\end{array}$ \\
\hline $\begin{array}{l}\text { Au et al. } \\
\text { (2010) }\end{array}$ & $\begin{array}{l}\text { CBT- } \\
\text { based MC }\end{array}$ & Group & $\begin{array}{l}\text { Face-to-face } \times 132 \mathrm{hr} \\
\text { sessions }\end{array}$ & $\begin{array}{l}\text { Guided by non-CBT } \\
\text { licensed facilitators } \\
\text { (trainee clinical } \\
\text { psychologists) }\end{array}$ & 26 & CES-D & Pre; post \\
\hline $\begin{array}{l}\text { Beauchamp } \\
\text { et al. (2005) }\end{array}$ & $\begin{array}{l}\text { CBT- } \\
\text { based MC }\end{array}$ & Individual & $\begin{array}{l}\text { Computerised } \\
\text { programme with no } \\
\text { fixed duration, } \\
\text { accessed 'as and } \\
\text { when' }\end{array}$ & Self-help & 0 & $\begin{array}{l}\text { BDI; STAI-S; } \\
\text { CSI }\end{array}$ & Pre; post \\
\hline $\begin{array}{l}\text { Blom et al. } \\
\text { (2015) }\end{array}$ & $\begin{array}{l}\text { CBT- } \\
\text { based MC }\end{array}$ & Individual & $\begin{array}{l}\text { Computerised } x 8 \\
\text { sessions with email } \\
\text { feedback }\end{array}$ & $\begin{array}{l}\text { Guided by CBT } \\
\text { licensed facilitator } \\
\text { (psychologist) }\end{array}$ & NR & $\begin{array}{l}\text { CES-D; } \\
\text { HADS-A }\end{array}$ & Pre; post \\
\hline $\begin{array}{l}\text { Chang } \\
(1999)\end{array}$ & $\begin{array}{l}\text { CBT- } \\
\text { based MC }\end{array}$ & Individual & $\begin{array}{l}\text { Telephone \& video } \\
\text { x } 8 \text { sessions of varied } \\
\text { duration }\end{array}$ & $\begin{array}{l}\text { Guided by non-CBT } \\
\text { licensed facilitators } \\
\text { (nurses) }\end{array}$ & NR & $\begin{array}{l}\text { BSI-A; BSI- } \\
\text { D }\end{array}$ & $\begin{array}{l}\text { Pre; post; } 1- \\
\text { month follow- } \\
\text { up }\end{array}$ \\
\hline
\end{tabular}


Guided by non-CBT

licensed facilitators

$\begin{array}{llllll}\begin{array}{l}\text { Chiu et al. } \\ \text { (2015) }\end{array} & \begin{array}{l}\text { CBT- } \\ \text { based } \\ \text { only }\end{array} & \text { Individual } & \begin{array}{l}\text { Face-to-face } x 31 \mathrm{hr} \\ \text { sessions }\end{array} & \begin{array}{l}\text { (care co-ordinators with } \\ \text { a background in } \\ \text { nursing, social work, } \\ \text { occupational therapy or } \\ \text { physiotherapy) }\end{array} & 3\end{array}$

\begin{tabular}{|c|c|c|c|c|c|c|c|}
\hline $\begin{array}{l}\text { Dowling et } \\
\text { al (2013) }\end{array}$ & $\begin{array}{l}\text { CBT- } \\
\text { based MC }\end{array}$ & Individual & $\begin{array}{l}\text { Face-to-face \& } \\
\text { videoconference x } 5 \\
1 \mathrm{hr} \text { sessions }\end{array}$ & $\begin{array}{l}\text { Guided by mixed non- } \\
\text { CBT licensed \& } \\
\text { licensed facilitators } \\
\text { (nurse specialists and a } \\
\text { psychologist) }\end{array}$ & 5 & $\begin{array}{l}\text { CES-D; ZBI; } \\
\text { PSS }\end{array}$ & $\begin{array}{l}\text { Pre; post; 1- } \\
\text { month follow- } \\
\text { up }\end{array}$ \\
\hline
\end{tabular}

$\begin{array}{llllll}\begin{array}{l}\text { Gallagher- } \\ \text { Thompson } \\ \text { et al. } \\ \text { (2008a) }\end{array} & \begin{array}{l}\text { CBT- } \\ \text { based MC }\end{array}\end{array} \quad \begin{array}{llll}\text { Group } & \begin{array}{l}\text { Face-to-face x12 2hr } \\ \text { sessions }\end{array} & \begin{array}{l}\text { Guided by non-CBT } \\ \text { licensed facilitators } \\ \text { (psychology graduates } \\ \text { and research fellows) }\end{array} & \begin{array}{l}\text { Pre; post; 2- } \\ \text { month follow- } \\ \text { up }\end{array}\end{array}$

Gallagher-

Thompson

et al.

CBT-
based MC Group

(2008b)
Face-to-face $\times 12$ 2hr sessions
Guided by non-CBT

licensed facilitators (psychology graduates and research fellows)
Pre, post; 2-

26

CES-D; PSS month follow-

up
Kajiyama et CBT-

al. (2013) based MC Individual
Computerised \&

bibliotherapy $x 6$

modules with no

time constraints
Self-help
0
CES-D; PSS Pre; post 


\begin{tabular}{|c|c|c|c|c|c|c|c|}
\hline $\begin{array}{l}\text { Steffen } \\
(2000)^{*}\end{array}$ & $\begin{array}{l}\text { CBT- } \\
\text { based } \\
\text { only }\end{array}$ & $\begin{array}{l}\text { Individual } \\
\text { Group }^{* \star *}\end{array}$ & $\begin{array}{l}\text { Telephone \& video } \\
\text { x8 30min video \& } \\
20 \text { min phone call..* } \\
\text { Face-to-face \& video } \\
\text { x8 90min group } \\
\text { including a } 30 \mathrm{~min} \\
\text { video within each } \\
\text { session*** }\end{array}$ & $\begin{array}{l}\text { Guided by non-CBT } \\
\text { licensed facilitators } \\
\text { (trainee clinical } \\
\text { psychologists) }\end{array}$ & 2.67 & BDI & Pre; post \\
\hline $\begin{array}{l}\text { Steffen and } \\
\text { Grant } \\
(2016)\end{array}$ & $\begin{array}{l}\text { CBT- } \\
\text { based MC }\end{array}$ & Individual & $\begin{array}{l}\text { Telephone, video \& } \\
\text { bibliotherapy } \times 1030 \\
\text { to } 50 \text { min phone call } \\
\& \times 1030 \text { min video } \\
\text { with workbook }\end{array}$ & $\begin{array}{l}\text { Guided by mixed non- } \\
\text { CBT licensed \& } \\
\text { licensed facilitators (x1 } \\
\text { clinical psychologist, x5 } \\
\text { non-licensed trainee } \\
\text { psychologists) }\end{array}$ & $\mathrm{NR}$ & $\begin{array}{l}\text { BDI-II; } \\
\text { MAACL-R-A }\end{array}$ & $\begin{array}{l}\text { Pre; post; 6- } \\
\text { month follow- } \\
\text { up }\end{array}$ \\
\hline $\begin{array}{l}\text { Tremont et } \\
\text { al. (2008) }\end{array}$ & $\begin{array}{l}\text { CBT- } \\
\text { based MC }\end{array}$ & Individual & $\begin{array}{l}\text { Telephone } x 23 \\
\text { phone calls, with } \\
\text { initial calls lasting } \\
1 \mathrm{hr} \& \text { follow-up calls } \\
\text { lasting } 15 \text { to } 30 \mathrm{mins}\end{array}$ & $\begin{array}{l}\text { Guided by non-CBT } \\
\text { licensed facilitators } \\
\text { (counsellor \& } \\
\text { psychology doctoral } \\
\text { student) }\end{array}$ & 12 & GDS; ZBI & Pre; post \\
\hline $\begin{array}{l}\text { Villareal- } \\
\text { Reyna et al. } \\
(2012)\end{array}$ & $\begin{array}{l}\text { CBT- } \\
\text { based MC }\end{array}$ & Group & $\begin{array}{l}\text { Face-to-face x8 } \\
90 \text { min sessions }\end{array}$ & $\begin{array}{l}\text { Guided by non-CBT } \\
\text { licensed facilitators } \\
\text { (nurses) }\end{array}$ & 12 & ISA & $\begin{array}{l}\text { Pre; post; } 1 \text { - } \\
\text { month follow- } \\
\text { up }\end{array}$ \\
\hline
\end{tabular}

Note. ${ }^{*}$ Composite study combining Steffen 2000a \& 2000b; ${ }^{* *}$ Steffen 2000a; ${ }^{* *}$ Steffen 2000b; NR = Not reported; CBT = Cognitive-

Behavioural Therapy; MC = Multicomponent; CES-D = Center for Epidemiological Studies Depression Scale; BDI = Beck Depression Inventory;

STAI-S = State-Trait Anxiety Inventory - State subscale; CSI = Caregiver Strain Instrument; HADS-A = Hospital Anxiety and Depression Scale 
- Anxiety subscale; BSI-A = Brief Symptom Inventory - Anxiety subscale; BSI-D = Brief Symptom Inventory - Depression subscale; ZBI = Zarit Burden Interview; PSS = Perceived Stress Scale; MAACL-R-A = Multiple Affect Adjective Check-list Revised - Anxiety subscale; GDS = Geriatric Depression Scale; ISA = Inventory of State Anxiety. 
Table 3. Overview of Intervention Groups and Control Groups for Included Studies

\begin{tabular}{ll}
\hline Study ID & Intervention overview \\
\hline Au et al. (2010) & $\begin{array}{l}\text { 'Coping with Caregiving' comprising a variety of cognitive and behavioural skills } \\
\text { and education about dementia caregiving }\end{array}$ \\
$\begin{array}{l}\text { Beauchamp et al. } \\
(2005)\end{array}$ & $\begin{array}{l}\text { Caregiver's Friend: Dealing with Dementia', worksite web-based intervention, } \\
\text { including knowledge, cognitive and behavioural skills, and affective learning }\end{array}$ \\
Blom et al. (2015) & $\begin{array}{l}\text { Mastery over Dementia' internet intervention, including problem solving, cognitive } \\
\text { restructuring, assertiveness training and relaxation }\end{array}$
\end{tabular}

Chang (1999)

Chiu et al. (2015)

Dowling et al (2013)

Gallagher-

Thompson et al. (2008a)

Gallagher-

Thompson et al.

(2008b)

Kajiyama et al.

(2013)

Steffen (2000)*

Steffen and Grant (2016) and education about dementia caregiving

iCare Stress Management' including cognitive and behavioural techniques, as well as information about dementia, behaviour management and communication skills

Anger management intervention including tension-reduction strategies, cognitive change strategies and assertion training

Teleheath behavioural coaching' including behavioural activation, behaviour management and relaxation

\section{Control type and Overview}

Waitlist

Waitlist

Non-active e-bulletins with practica information e.g. holiday breaks

Non-active attention control

Treatment as usual

Non-active attention control

Non-active empathic telephone calls and postal information about dementia

Non-active empathic telephone calls and postal information about dementia
Non-active generic education about dementia

Waitlist

Treatment as usual 
Tremont et al. $\quad$ Family Intervention: Telephone Tracking - Dementia' (FITT-D), including active (2008)

Villareal-Reyna et al. (2012)

\section{Treatment as usual}

Non-active 'home accident prevention' information group

Note. *Composite study combining Steffen 2000a \& 2000b; ${ }^{* *}$ Steffen 2000a; ${ }^{* *}$ Steffen 2000b; NR = Not reported. 
Table 4. Quality Rating Sub-total Scores for Studies Included in the Second Empirical Paper

\begin{tabular}{|c|c|c|c|c|c|c|c|c|c|}
\hline \multirow[b]{2}{*}{ Study ID } & \multicolumn{7}{|c|}{ Outcome Measures } & \multirow[b]{2}{*}{$\begin{array}{l}\text { Overall } \\
\text { Quality of } \\
\text { Study } \\
\text { Conclusions } \\
(\max =2)\end{array}$} & \multirow[b]{2}{*}{$\begin{array}{l}\text { Total } \\
\text { Quality } \\
\text { Rating (\%) }\end{array}$} \\
\hline & $\begin{array}{l}\text { Description } \\
\text { of } \\
\text { Participants } \\
(\max =10)\end{array}$ & $\begin{array}{l}\text { Definition } \\
\text { and } \\
\text { Delivery of } \\
\text { Intervention } \\
(\max =10)\end{array}$ & $\begin{array}{l}\text { Inclusion of } \\
\text { Social } \\
\text { Significance }\end{array}$ & $\begin{array}{l}\text { Inclusion of } \\
\text { Social } \\
\text { Validity }\end{array}$ & $\begin{array}{l}\text { Outcome } \\
\text { Measures } \\
\text { Total } \\
(\max = \\
12)\end{array}$ & $\begin{array}{l}\text { Data } \\
\text { Analysis } \\
\text { (max = } \\
10)\end{array}$ & $\begin{array}{l}\text { Intervention } \\
\text { Assignment } \\
(\max =8)\end{array}$ & & \\
\hline $\begin{array}{l}\text { Au et al. } \\
(2010)\end{array}$ & 5 & 5 & No & No & 4 & 2 & 4 & $x^{2}=y_{1}$ & $\begin{array}{l}\text { Moderately } \\
\text { poor (40.7) }\end{array}$ \\
\hline $\begin{array}{l}\text { Beauchamp } \\
\text { et al. (2005) }\end{array}$ & 2 & 2 & No & Yes & 3 & 3 & 4 & 1 & $\begin{array}{l}\text { Moderately } \\
\text { poor (34.7) }\end{array}$ \\
\hline $\begin{array}{l}\text { Blom et al. } \\
(2015)\end{array}$ & 7 & 3 & No & No & 7 & 7 & 5 & 1 & $\begin{array}{l}\text { Average } \\
(57.6)\end{array}$ \\
\hline $\begin{array}{l}\text { Chang } \\
\text { (1999) }\end{array}$ & 2 & 1 & No & No & 4 & 4 & 4 & 2 & $\begin{array}{l}\text { Moderately } \\
\text { poor (33.9) }\end{array}$ \\
\hline $\begin{array}{l}\text { Chiu et al. } \\
(2015)\end{array}$ & 2 & 3 & No & No & 7 & 6 & 6 & 2 & $\begin{array}{l}\text { Average } \\
(50.8)\end{array}$ \\
\hline $\begin{array}{l}\text { Dowling et } \\
\text { al. (2013) }\end{array}$ & 4 & 3 & No & Yes & 5 & 2 & 4 & 1 & $\begin{array}{l}\text { Moderately } \\
\text { poor (35.6) }\end{array}$ \\
\hline $\begin{array}{l}\text { Gallagher- } \\
\text { Thompson } \\
\text { et al. } \\
(2008 a)\end{array}$ & 6 & 6 & No & No & 6 & 5 & 4 & 1 & $\begin{array}{l}\text { Average } \\
(54.2)\end{array}$ \\
\hline $\begin{array}{l}\text { Gallagher- } \\
\text { Thompson } \\
\text { et al. } \\
(2008 b)\end{array}$ & 6 & 6 & No & No & 6 & 5 & 4 & 1 & $\begin{array}{l}\text { Average } \\
(54.2)\end{array}$ \\
\hline
\end{tabular}




\begin{tabular}{|c|c|c|c|c|c|c|c|c|c|}
\hline $\begin{array}{l}\text { Kajiyama et } \\
\text { al. (2013) }\end{array}$ & 8 & 2 & No & Yes & 5 & 5 & 5 & 2 & $\begin{array}{l}\text { Moderately } \\
\text { good } \\
(63.3)\end{array}$ \\
\hline $\begin{array}{l}\text { Steffen } \\
(2000)^{*}\end{array}$ & 5 & 8 & No & Yes & 3 & 3 & 4 & 1 & $\begin{array}{l}\text { Average } \\
(45.8)\end{array}$ \\
\hline $\begin{array}{l}\text { Steffen and } \\
\text { Grant } \\
(2016)\end{array}$ & 8 & 4 & Yes & No & 8 & 5 & 7 & 1 & $\begin{array}{l}\text { Moderately } \\
\text { good } \\
(62.7)\end{array}$ \\
\hline $\begin{array}{l}\text { Tremont et } \\
\text { al. (2008) }\end{array}$ & 7 & 6 & No & Yes & 8 & 3 & 5 & 1 & $\begin{array}{l}\text { Average } \\
(55.9)\end{array}$ \\
\hline $\begin{array}{l}\text { Villareal- } \\
\text { Reyna et al. } \\
(2012)\end{array}$ & 9 & 6 & No & No & 4 & 6 & 2 & 1 & $\begin{array}{l}\text { Average } \\
(54.2)\end{array}$ \\
\hline
\end{tabular}

